\title{
CONTRIBUIÇÃO GOVERNAMENTAL NA ASCENSÃO DO MODELO AGROEXPORTADOR DO AGRONEGOCIO E SUAS CONSEQUENCIAS SOCIAIS E AMBIENTAIS ${ }^{1}$
}

\author{
Benjamin Alvino de Mesquita \\ Universidade Federal do Maranhão (UFMA)
}

\begin{abstract}
CONTRIBUIÇÃO GOVERNAMENTAL NA ASCENSÃO DO MODELO AGROEXPORTADOR DO AGRONEGOCIO E SUAS CONSEQUENCIAS SOCIAIS E AMBIENTAIS

Resumo: A proposição do texto é analisar, de forma pontual, a importância da contribuição do Estado no processo de constituição e consolidação do modelo agroexportador, dando ênfase à análisedas consequências sociais e ambientais decorrentes dessa transformação na atualidade. Destaca que a exportação de commodity, efetivada por um poderoso complexo agroindustrial consolidado no passado, agora mais sofisticado e denominado de agronegócio, assume papel semelhante ao que teve no passado. Pondera que a razão para tal estaria no peso da representatividade política e econômica das exportações para o PIB, balanço de pagamento, renda e o emprego. Argumenta que, num confronto superficial do padrão de ocupação, das estratégias utilizadas e do legado deixado no caminho dessa expansão, surgem elos comuns, concluindo que os resultados positivos para a sociedade envolvida não são animadores, na medida em que prevalece um rastro de saques e pilhagem e um imenso passivo social e ambiental perverso.
\end{abstract}

Palavras-chave: Agronegócio, atuação governamental, forças de mercado, modelo agroexportador.

GOVERNMENTAL CONTRIBUTION IN THE AGRICULTURAL EXPORT AGRIBUSINESS MODEL ASNCENSION AND ITS SOCIAL AND ENVIRONMENTAL CONSEQUENCES

Abstract: This paper aims to show in an exact manner the importance of the state contribution in the process of formation and consolidation of the agriexport model and analyze the social and environmental consequences of this transformation today. It is noticed that the export commodity, carried by powerful agroindustrial complex consolidated in the past, now much more sophisticated, and called agribusiness, assumes a similar role that had in the past. Ponders that the reason would be political and economic representation representing exports to GDP, payment balance, income and employment. Argues that, in a superficial comparison of the pattern of occupation of the strategies used and the legacy left in the way of this expansion, there are common links, concluding that, the positive results for the company involved are not encouraging; one prevails looting and pillage trail and a huge perverse social and environmental liabilities.

Key words: Agribusiness, government action, market forces, agriexport model. 


\section{INTRODUÇÃO}

O presente texto se propõe mostrar de forma pontual a importância da contribuição do Estado no processo de constituição e consolidação do modelo agroexportador (e, das suas mudanças atuais) e analisar as conseqüências sociais e ambientais decorrentes desse modelo na atualidade.

Essa opção política e econômica para viabilizar a criação e apropriação de excedente a um restrito e privilegiado grupo de produtores agrícolas (os grandes proprietários e os setores a eles articulados) vinculados ao mercado externo consubstanciado ao longo do nosso processo de formação econômica foi responsável pela criação e consolidação de um modelo de desenvolvimento excludente e de privilegio a essa classe social. Apesar do modelo sofrer alterações ao longo desse período, a essência do mesmo, que se baseia na apropriação e controle dos recursos naturais e na expropriação sistemática de todos os que estão na sua rota de expansão, se mantém intacta.

Esse padrão agroexportador do Século XIX e XX, baseado nas vantagens comparativas e no consumo e na destruição voraz de recursos naturais, calcado na grande propriedade, no trabalho escravo (depois substituído pelo colonato e assalariado); na especialização da produção de poucos produtos; concentrado em área especificas e no vínculo com o mercado externo, tinha por base de apoio as políticas publicas governamentais, onde o subsidio e privilégios de toda ordem assegurava e garantia o processo de acumulação nessa atividade agroexportadora.

O mercado externo e a ação governamental são assim elementos cruciais para a formação, consolidação e hegemonia do setor, mas também fatores de vulnerabilidade desde sua formação $A$ derrocada da cafeicultura nos anos trinta do século vinte e a substituição do modelo agroexportador que tinha no mercado externo sua dinâmica de crescimento, por um modelo voltado a substituição de importação (industrialização) onde o mercado interno e a urbanização sobressaem atesta isso.

No entanto desta ação conjunta e permanente, entre estado e capital, se compreende o papel que essa minoria privilegiada assume em termos econômico, social, político e cultural na sociedade brasileira (e, também na latina americana). Durante séculos essa elite agrária, o capital mercantil, bancário e ação governamental comandam a sua maneira o crescimento econômico destas economias mesmo convivendo com vulnerabilidade e a instabilidade própria de economias agroexportadoras. As constantes crises econômicas do século XIX e XX e expõe a fragilidade desta economia e a necessidade de encontrar alternativas a essa dependência crônica as exportações de produtos primários.
Ou seja, os mesmos elementos que num momento Ihe favorecia a expansão e sua hegemonia, são também os responsáveis pela sua queda, nos anos 1930, e sua substituição pelo setor urbano e industrial. Ação governamental desde então é formar e consolidar um setor industrial pela via de substituição de importação, cujo resultado nos anos 1960 e seguintes, é a produção interna de maquinas, equipamentos e insumos que possibilitará a implantação plena de um projeto de modernização da agricultura nos moldes da Revolução Verde vendida como alternativa ao crescimento econômico via produção de excedente exportável (TAVARES, 1988).

Adoção por parte do governo dos princípios da Revolução Verde baseado na quimificação dos solos, mecanização e semente melhoradas possibilitou uma modernização e industrialização rápida da agricultura e mudança do seu perfil. A intervenção governamental (pós golpe militar de 1964) via credito rural subsidiado, pesquisa, política de preços mínimos, incentivos fiscais permitiram que num curto espaço de tempo, a produção e a produtividade de produtos voltados às exportações e/ou substituição de combustíveis deslanchassem. Além disso, os incentivos e as políticas setoriais também viabilizam a criação e consolidação dos diferentes elos da cadeia produtiva - a jusante e a montante - fundamental na implementação e sustentação de uma agricultura capitalista, industrial e de larga escala importante na produção de excedentes exportáveis (KAGEYAMA, 1990; MESQUITA, 2006).

De forma que quando a crise econômica dos anos 1980 se aprofunda e o Estado encolhe e perde o papel proativo que tinha na condução da política setorial da agropecuária, o setor moderno da agricultura de exportação (complexos agroindustriais) já se encontra estruturado e integrado na sua plenitude. Um novo padrão de acumulação, liderado por cadeias agroindustriais consolidadas, passa a prevalecer e se articular mais amiúde com outros blocos do capital, o bancário, industrial e comercial até então desinteressados na agricultura (KAGEYAMA, 1990; GRAZIANO DA SILVA, 1996; MESQUITA, 2012).

Este cenário apresentado permite que se compreenda o modelo agroexportador atual do agronegócio, aqui entendido com um sistema integrado constituído por diversas partes/elos que representa o todo. Ou seja, nos moldes dos complexos agroindustriais e/ou das cadeias produtivas consolidadas e atuantes nos anos 1980. De outra forma, o agronegócio é não visto como algo diferente daquilo pensado por Davis e Goldberg (1957) onde a idéia é ver os links pro e pós porteira, que se estabelece com agricultura e os demais setores a jusante a montante na medida em que ela se industrializa e se torna mais complexa.Também 
não se comunga da idéia de que hoje esse modelo agroexportador do agronegócio constituía em um novo padrão de acumulação na atividade e que o sucesso do mesmo se deva as forças de mercado (empresas globais,capital financeiro) que substituiu ação estatizante que prevalecia anteriormente.

$\mathrm{Na}$ verdade um equívoco, a base dessa expansão interrupta desde meados dos anos 1990, já estava dada e consolidada pela política de modernização e programas especiais implementados anteriormente na expansão de grãos na fronteira agrícola. Além do mais é preciso alertar que a ação governamental não desaparece no período neoliberal, o que houve foi uma mudança de sua ação que deixa de ser setorial para ser mais abrangente, onde a política macroeconômica ortodoxa via cambio, taxa de juro e impostos (Lei Kandir) e o investimento em infraestrutura voltada à exportação sobressaem. Naturalmente o crescimento da demanda externa impulsiona esse boom das commodities nesse período, mas o peso maior está no equacionamento de entraves efetivados pelo estado em termos de equalização de dívidas anteriores e de incentivos a exportação de commodities em geral, cujo eixo central se encontra na desoneração das exportações prevista na Lei Kandir.

Aprovação da Lei Kandir em 1996 constitui um marco para o setor de commodity, pois desonera de imposto as exportações de matérias-primas e onera os produtos semi e industrializados. Se de um lado ela favorece a expansão interna da produção e externamente a torna mais competitiva, do outro, ela incentiva a atividade extrativa e/ou economia de enclave que pouco contribui para o desenvolvimento local ou até para uma desindustrialização, além de deteriorar o sistema de arrecadação dos estados exportadores de commodities. Wesz Júnior (2014, p. 52), mostra que o efeito da mesma e da desvalorização cambial foi imediato,

[...] de 1996 a 1998, a soja exportada em grão passou de $5 \%$ a $30 \%$ (percentual sobre a produção colhida). Entre 1995 a 2011 a produção cresceu $250 \%$,as exportações ampliou em dez vezes, enquanto a soja destinada a esmagamento e processamento ficou em $60 \%$.

Além dessa introdução e considerações finais, o texto está organizado em três partes: a) Aspectos gerais da evolução do modelo agroexportador, b) A ascensão do agronegócio, a atuação governamental e do mercado, c) O modelo agroexportador e as conseqüências sociais e ambientais. Na primeira dela se faz um apanhado histórico da evolução desse modelo agroexportador ressaltando a importância que a agricultura de exportação exerce no desenvolvimento econômico, bem como as mudanças processadas nesse período. Chama-se também atenção para o decisivo papel da atuação governamental no sucesso desse padrão atual denominado de agronegócio. Na parte seguinte procurou-se mostrar que a ascensão dos complexos agroindustriais, na década de 1990 está articulada com a presença de empresas globais na área de produção, beneficiamento e comercialização e, sobretudo como o formato que assume as políticas macroeconômicas de cambio, monetária, fiscal e outros setoriais adotados pelo Estado no contexto das reformas neoliberais. Por ultimo procurou alertar que esse padrão predatório de expansão das commodities tem gerado custos sociais e ambientais marcantes que estão sendo postergados. Além de referencia relacionada à temática abordada, se utilizou também de dados oficiais disponibilizados nos sites do Instituto Brasileiro de Geografia e Estatística (IBGE) e Instituto Nacional de Pesquisas Espaciais (INPE) e, de um relatório de campo realizada em Balsas-MA.

\section{ASPECTOS GERAIS DA EVOLUÇÃO DO MODELO AGROEXPORTADOR}

Conforme nos ensina os clássicos, Furtado (1997), Caio Prado Jr. (1976), Castro (1977), a especialização em atividade agropecuária vinculada ao mercado externo e produzida em larga escala, em grande latifúndio na América Latina não constitui novidade; na verdade, foi e é uma tradição dessa sociedade e cumpriu funções importantes na formação econômica, social, política e cultural desses países. Coube a ela um papel essencial, qual seja o de gerar divisas para importação de bens e serviços não produzidos internamente, mas também o de principal provedor de recursos para as finanças locais via imposto de exportação.

Ou seja, o sucesso externo dos produtos exportáveis exercia uma função preponderante, pois tinha como responsabilidade a obtenção de moeda forte para importar. Daí a relevância que assume e o apoio que recebe, em situações de crise. Isso era possível porque a elites política e econômica se confundiam e se revezavam no poder e nessas atividades lucrativas. Assim, em período de crise dos preços externos, a política econômica (desvalorização cambial) adotada era no sentido de compensar essas perdas (FURTADO, 1997).

Para garantir, em longo prazo esse caráter especializado e rentável, prevalecente nas atividades coloniais dominadas pela elite agrária, pressupunha que outras condições internas fossem satisfeitas, como a incorporação de extensas áreas de terra e a farta oferta de mão de obra para as suas plantations, já que o padrão de organização era a grande propriedade e/ou o trabalho servil/ livre (FURTADO, 1997). Cabe, portanto, ao Estado fazer isso e/ou estimular que terceiros o façam. As guerras de conquista e o açambarcamento de territórios livres e indígenas marcam o início dessa 
limpeza da fronteira para os latifundiários. Ou seja, é a pilhagem organizada e autorizada que comanda esse processo de acumulação primitivo desse período que perpassa séculos adentro. O saque e a expropriação são as palavras de ordem (MARX, 1971).

A resultante desse modus operandi é a formação de uma sociedade extremante estratificada/segmentada, uns com direito a tudo, outros sem direito a nada. A minoria elite agrária explora a atividade lucrativa articulada com o mercado externo, e retém o excedente; a outra parte, formada de pequenos produtores, proprietário e não proprietários, responsável pela produção de alimentos e oferta de força de trabalho que é a maioria, gera e transfere esse excedente. Ela se encontra espoliada e atomizada em todo o território, produzindo e desempenhando papéis fundamentais nas suas economias locais/regionais em termos de abastecimento interno, ocupação e/ ou reservatório dessa força de trabalho. Apesar da invisibilidade perante o poder público, a pequena produção de alimentos teve e tem uma função das mais importantes, seja na retenção da população no campo, na geração e distribuição da riqueza gerada e/ou na formação e manutenção de núcleos urbanos fora do circuito agroexportador (PRADO JR., 1976; CASTRO, 1977).

Desde os tempos coloniais, o modelo agroexportador baseado em plantation e na criação de gado, efetivada em grande propriedade, controlada pela elite local e vinculado ao mercado externo, exerceu um papel importante na economia dos países latino-americanos, tanto no plano econômico quanto no plano político.

A criação de gado, no Brasil (e, em outros países latino-americanos), por exemplo, constituiu um dos mais importantes fatores de conquista e consolidação de territórios, assumindo, assim, um papel estratégico na geopolítica das metrópoles coloniais e dos Estados Nacionais que emergem posteriormente. A produção e a exportação de produtos, como o açúcar e café no Brasil, pela centralidade que assume no plano econômico se tornam o eixo central de acumulação nessas sociedades coloniais e na sua continuidade posterior. Outras atividades da agropecuária, mas com ciclo econômico mais curto, como a borracha (Amazônia), a erva-mate, (Sul), o algodão, cacau e o couro (Nordeste), também desempenharam papeis importantes em suas economias, embora com pouca ou quase nenhuma articulação entre si destes núcleos econômicos (FURTADO, 1997).

Esse quadro de dicotomia social/econômico do período colonial, com as devidas adaptações, estende-se por séculos, sendo interrompido pela crise de 1929, quando os Estados Nacionais dos países latino-americanos põe em segundo plano esse modelo agroexportador (o mercado externo) e passam a privilegiar a industrialização (mercado interno) como forma de sair da crise e da dependência as exportações.

Durante o período colonial, e até a grande crise econômica de 1929, a agricultura, detém a centralidade da dinâmica econômica, pois é a responsável maior pela geração de renda e emprego e obtenção de divisas essenciais às importações de produtos manufaturados e ao pagamento dos juros da dívida externa contratada do período (FURTADO, 1997). Além disso, essa agricultura de exportação ao espraiar o excedente apropriado na atividade, em outros ramos econômicos ligadas a serviços, comércio, indústria, estrada de ferro, portos, companhia de seguro e bancos, possibilita a formação de um complexo econômico que se articular entre si contribuindo para o desenvolvimento econômico e uma rápida urbanização de regiões inteiras vinculadas direta ou indiretamente a atividade principal. Para Cano (1983) é a expansão da cafeicultura em molde capitalista, ao formar o complexo cafeeiro, que explica a rápida e precoce ascensão econômica de São Paulo já no final do século XIX.

A crise de 1929 traz assim uma mudança no papel do estado e com ela uma reestruturação produtiva em termos de substituição e diversificação da produção, com o objetivo de atender ao mercado interno e compensar a retração do mercado externo. Ou seja, se rompe o padrão liberal, então vigente da ortodoxia econômica segundo a qual as forças de mercados equacionaria tudo, por outro intervencionista, onde o Estado passa assumia funções proativas na condução de outro novo modelo (padrão de acumulação) de desenvolvimento que tem na industrialização interna (substituição de importação) e no gasto publico seu pilar de sustentação, a agricultura, por exemplo ,passa a desempenhar o papel de supridor de matériaprima para a indústria nascente e de alimentos a preços baixos para a ascendente força de trabalho urbana,indispensáveis para a acumulação de capitais no setor mais dinâmico da economia - a indústria (OLIVEIRA, 1975).

Até a consolidação de parques industriais (década de 1970), em alguns países latinoamericanos - Argentina, Brasil e México, resultante da política de substituição de importação, representou a abertura de novos horizontes a expansão da agricultura, tanto a de exportação quanto a de mercado interno que se encontrava então, tecnicamente travada.

O lançamento dos princípios da Revolução Verde nos anos 1960 dá uma reviravolta na estagnação da agricultura, que volta a assumir funções importantes na economia pós 1964. Aadesão do governo e a adoção de medidas econômicas, como o crédito rural farto e subsidiado, os incentivos econômicos para a instalação de indústria a jusante 
e a montante do setor e a exportação de excedentes, viabilizou a modernização do setor em curto espaço de tempo e ocasionou mudanças importantes no perfil produtivo da agricultura propriamente dita. Possibilitou também a formação e consolidação de importantes grupos oligopólios a jusante e a montante da atividade modernizando e tornando mais complexa a inter-relação entre os elos da atividade, mas privilegiando novamente segmentos muito específicos, a grande propriedade, produtos de exportação e /ou energéticos e as indústrias dos diferentes elos articulados com a modernização (MESQUITA, 2012, 2011b).

A modernização conservadora da agricultura pós 1960, mesmo que se realize de forma parcial, pontual e residual reforçou ainda mais a concentração e a centralização do capital, já presente em outros setores econômicos, e também engendrou um novo padrão de acumulação cuja característica maior foi o uso intensivo de processos mecanizados e de insumos modernos e sob a égide dos complexos agroindustriais. Esse modelo de modernização produtivista e destruitivista gerou um custo social e ambiental incomensurável, que se aprofunda nos anos 1990, com a nova ordem liberal. O novo cenário econômico, patrocinado pela demanda chinesa e reformas do Estado cria espaço para a entrada de novos atores, que já estavam presentes, mas que não tinham essa visibilidade que detêm na década atual.

Trata-se da volta de cadeia produtiva já presente no complexo da carne, fumo, celulose, cana e soja, só que agora internacionalizada, mais sofisticados e atuando em escala planetária na produção e controle da oferta e dos mercados de commodities agrícolas, sob a égide de tradings, cartéis, holding, fundos soberanos e de pensões e até de empresas estatais estrangeiras (a chinesa Chongqing Grain Group). Esse agrobusiness (ou complexos agroindústrias/cadeias agroindustriais, como eram chamadas nos anos 1990), a mídia e entidade de classe passa a traduzir por agronegócio e representar o que há de eficiente e moderno no campo e, a exercer um poder político e econômico incompatível com o que recebe em termos de recursos da sociedade. Segundo Delgado (2012, p. 4) embora haja semelhanças em aspectos econômicos, entre a atual economia do agronegócio e as cadeias agroindustriais da modernização conservadora, os dois dependem de subsídios e recursos naturais, para ele o arranjo político e ideológico é outro,

[...] o arranjo político atual é diferente do anterior. A economia do agronegócio vai além da estratégia econômica para construir ideologicamente uma hegemonia pelo alto - da grande propriedade fundiária, das cadeias agroindustriais muito ligadas ao setor externo e das burocracias de Estado

\section{SUAS CONSEQUENCIAS SOCIAIS E AMBIENTAIS}

\begin{abstract}
(ligadas ao dinheiro e à terra) -, tendo em vista realizar um peculiar projeto de acumulação de capital pelo setor primário. Essa estratégia tem agora certa centralidade no sistema econômico, diferentemente da subsidiariedade à industrialização, como fora no passado. A esse projeto, fortemente assentado na captura e superexploração das vantagens comparativas naturais ou de sua outra face da moeda - a renda fundiária -, somam-se vários aparatos ideológicos, ausentes na modernização conservadora.
\end{abstract}

E, para Gras (2013, p. 1) o agronegócio em função de uma reorganização do formato de atuação de frações diversas do capital no agrário e da presença de aspectos antes inexistente como as sementes transgênicas, agronegócio representaria um novo paradigma de agricultura e, portanto um novo padrão de acumulação,

\begin{abstract}
El agronegocio sintetiza de manera paradigmática la nueva agricultura, al establecer conceptualmente los vínculos entre los cambios en el conocimiento científico y sus impactos en la reorganización de los sistemas de innovación, las modificaciones en el plano jurídico y regulatorio, las transformaciones en los sistemas productivos (con la participación creciente del capital financiero, cambios en la estructura de tenencia de la tierra reorganización del trabajo, etc.) y en el perfil de los actores participantes.
\end{abstract}

Os argumentos são até pertinentes, no entanto, apenas problematiza as relações já existentes anteriormente, essas especificidades apontadas pouco alteram a questão central do modelo agroexportador (do antigo ou do atual) que é a busca fácil do lucro e a captação da excedente calcada nas vantagens comparativas proporcionadas pelo controle e monopólio da terra e que só se sustentam pela ação governamental que viabiliza esse processo histórico de acumulação. De forma que o aperfeiçoamento técnico e a maior articulação política são mais um apêndice dessa relação política e histórica construída entre o estado e o capital.

\section{A ASCENSAODOAGRONEGOCIOEATUAÇÃO GOVERNAMENTAL E DO MERCADO}

Ascensão do agronegócio, particularmente o da soja, se insere em dois movimentos que ocorrem simultaneamente, de um lado a implementação interna pelo Estado das reformas neoliberais que levam a uma rápida globalização comercial e, sobretudo financeira, na década de 1990, e do outro, o boom econômico, sobretudo chinês, que se desdobra no aumento da demanda e do preço de commotidy. Essa conjuntura possibilitou 
uma maior circulação de mercadorias, serviços e capital, no comércio internacional de commodities, beneficiando não só as economias que tinham tradição nesse segmento de produtos, como outras que passam a incorporar a esse fluxo de comércio, ocasionado, pela demanda chinesa por produtos agrícolas (MESQUITA, 2013).

Naatualidade(séc. XXI), umconjuntodepouco mais de uma dezena de complexos agroindustriais, liderado por grandes conglomerados financeiros nacionais e estrangeiros, controla parte importante da produção, financiamento, comercialização e fatias crescente do processamento e da industrialização dessas matérias-primas em escala global, e está presente em todos os países onde a produção e exportação é relevante. Eles são os responsáveis diretos ou indiretos pelo crescimento significativo das mesmas que se verificou nas últimas décadas, e, dependendo do país, respondem por uma parcela importante das exportações agropecuárias e do emprego e conseqüentemente, pela entrada de dólares no país, cujas estimativas estão entre $27 \%$ e $36 \%$, variando de acordo com o período analisado e o país (MESQUITA, 2013)2.

O efeito da nova divisão do trabalho nos países fornecedores de matérias-primas para a China e para o mundo industrializado é o aumento, nesses países periféricos, do numero de empresas globais interessadas na esfera da produção de tais commodities, já que anteriormente a atuação era focada na comercialização. A entrada massiva das grandes empresas produzindo e financiando médios e grandes produtores, veio acompanhado do interesse de trades, fundo de investimento, bancos e holding, aspecto importante na canalização de investimentos para as atividades estratégicas e na internalizarão do setor. Assim adoção de políticas governamentais neste novo cenário neoliberal direcionado a esse segmento, com o objetivo de atender à demanda externa e incorporar novas áreas ao processo produtivo foi imprescindível.

Além disso, como a competição por mercados globais e por novas áreas de plantio faz parte da estratégia permanente dessas empresas globais, nota-se uma tendência no aumento da produção e da concentração e centralização de capitais em áreas estratégicas, como a dos biocombustíveis, e a compra e arrendamento de terra por esse segmento do capital. ${ }^{3}$ Tendência que não se consta nas culturas voltadas para o abastecimento interno e/ ou com preços deprimidos, aqui houve um revés de crescimento (lento ou negativo) ou de substituição por outras atividades mais lucrativas. A antiga dicotomia, entre grandes produtores e produtos de exportação e entre agricultura familiar e mercado interno, ganha uma nova dimensão em função de novos atores presente no financiamento da produção e comercialização. No formato atual, além de bancos estatais o financiamento também está respaldado nos grandes conglomerados e fundos de investimentos nacionais e estrangeiros.

No Brasil e na Argentina a produção da soja se generalizou de tal forma, concentrando e especializando regiões inteiras, que outras culturas desapareceram e/ou se encontram espremidas, sem alternativas de crescimento. Em qualquer região do país a proporção entre soja e outros produtos temporários é muito desigual e preocupante ${ }^{4}$.

O crescimento econômico recente do agronegócio é liderado pela presença de grandes empresas, particularmente em atividades e áreas articuladas com o mercado externo, em que as commodities, nas últimas décadas, assumem um papel relevante. Os instrumentos governamentais de base fiscal e monetária, além de outros utilizados pela antiga política de desenvolvimento regional, comuns e importantes no período do Estado desenvolvimentista (1970-1985), continuam sendo, em pleno século XXI, a marca registrada na atração de mega investimentos.

Embora haja dezenas de grupos nacionais de médio e grande porte presentes nos diferentes elos de cada cadeia produtiva do agronegócio, sabe-se que, no nível mais geral da comercialização e do processamento, ele é dominado por grupos estrangeiros, verdadeiros cartéis do setor, poderosos, financeira e politicamente em todos os países que têm relevância na produção e processamento de grãos, em especial a soja, e na comercialização e distribuição dos seus derivados.

As grandes tradings internacionais, ADM, Bunge, Cargill Dreyfus e o grupo nacional Amaggi (A.B.C.D e Am) controlam parcela significativa dessa atividade nos diferentes elos da cadeia produtiva. Elas são as principais engrenagens que explicam esse avanço vigoroso do agronegócio no Brasil e em outros países onde atuam. Outros complexos como da celulose (eucalipto) e do óleo de palma (dendê) também são controlados por gigantes como a Vale, Petrobras, Suzano, Galp e Votorantim, com enorme poder de mercado nos segmentos em que atuam (MESQUITA, 2013).

Além desse grupo poderoso das tradings que dominam o processamento e o comércio especialmente de soja no mundo inteiro, há também um grupo de grandes empresas de capital aberto e fechado que atua, sobretudo na produção e prestação de serviços e em áreas de fronteira a agrícola do cerrado do MATOPITA ${ }^{5}$ (e também no Uruguaio e Paraguaio). A característica marcante desse grupo é o modelo de produção que combina altíssima escala gestão profissional e acesso aos mercados de capitais. As principais são Agrifirma, Weisul e Xingu Agri (subsidiária da trading Multigrain), SLC Agricola, Ceagro, Tiba Agro, Vision Brazil Investments, Agroconsult, Vanguarda Agro, Brasilagro, Insolo (loschpe), Agrinvest, Ceagro (holding do grupo argentino Los Grobo). A estimativa 
é que essas empresas tenham o controle de mais de hum milhão de hectares nessa região do cerrado, sendo que a SLC agrícola c e a Tiba agro são as mais representativas quanto ao controle de área.

Há um aspecto que para alguns é inusitado nessa expansão recente da soja e eucalipto, na fronteira agrícola do MATOPIBA, que é o controle da terra (propriedade) por grandes grupos empresariais sem a necessidade de sua compra. Ela acontece via arrendamento da área e/ou contrato de integração com o grupo empresarial.

Tal Estratégia tem sido muito utilizada por grupos argentinos para aumentar rapidamente a produção em período de boom sem a necessidade de imobilizar investimento em terra. Essa formatação permite ao proprietário sem experiência na atividade (primeira situação) usufruir uma renda fundiária, pelo o monopólio da terra que detém sem o risco inerente a atividade, no segundo caso a remuneração varia com o tipo de integração e implica em riscos maiores.

Embora a margem de remuneração recebida seja inferior a vigente no mercado, a alternativa de entrar para competir como esse empreendedor global gera insegurança e deixa o iniciante numa posição vulnerável, dada que a atividade é controlada por trustes nos diferentes elos da cadeia produtiva. Tanto a jusante quanto a montante, e mesmo nos outros elos relativos a prestação de serviço, assistência técnica, financiamento e comercialização são cada vez mais também controlados por oligopólios. Dessa forma muitos médios e mesmo grandes produtores têm se adaptado e evitado correr risco endógeno relativo à dinâmica das commodities agrícolas, ou seja, cedem o controle e mas mantêm a propriedade da terra.

Esse conjunto de grandes empresas, sem dúvida, detém um poder de mercado importante que chegam a sinalizarem as tendências e estratégias e, conseqüentemente, a ampliação ou recuo da área plantada e/ou do processamento a ser feito, e, claro, das exportações e mercados a atingir no médio e longo prazo. Dessa forma, o avanço das áreas com dendê, eucalipto e soja, nos biomas do Pantanal, do Cerrado e da Amazônia, vincula-se fundamentalmente a tais decisões empresariais, mas de olho nas ações governamentais. Por sua vez, essa decisão das empresas depende da tendência geral do crescimento econômico das economias que hoje ditam a dinâmica do mundo capitalista, no caso a chinesa e a norte-americana. É a partir da demanda desses gigantes que se compreendem o rumo das mudanças no plano espacial e o ritmo frenético que assume determinada atividade frente às demais (MESQUITA, 2006).

A soja é uma das mais importantes fontes de proteínas do mundo e sua produção tem crescido rapidamente, nas ultimas décadas tanto nos tradicionais países produtores China, Índia, USA, Brasil e Argentina, como em outros,
Paraguaio, Uruguaio, Bolívia. Por ordem de importância atualmente três se destacam na oferta e na exportação, USA, Brasil e Argentina. O Brasil é o maior exportador e, ultimamente reversa com os americanos a primeira posição também na produção a tendência é que no curto prazo o Brasil assume definitivamente essa posição.

O crescimento da soja no país nas ultimas décadas alcançou patamares significativos, saiu de 20 milhões de toneladas em 1990, para 87 milhões de toneladas em 2014 , ou seja, aumentou $436 \%$, isto é, cresceu $6,3 \%$ ao ano. Área ocupada pela soja saltou de 11,5 milhões para 30,3 milhões de hectares, ou $261 \%$, como a produtividade no período cresceu apenas $173 \%$, isso significa que o aumento da produção decorreu muito mais da expansão da área do que da produtividade, isto é, cerca de $60 \%$ de sua expansão vem da incorporação de novas áreas. Isso mostra que ao contrário do discurso vigente de que a terra é secundária no atual modelo, as evidencias mostram o contrário, a sua propriedade e o controle ainda continua marcante no agronegócio, portanto é ela quem garante parte desse festejado ciclo de expansão.

Os dados do Censo de 2006 revelam também um marcante grau de concentração na atividade. 0 numero de estabelecimentos (familiar e patronal) ${ }^{6}$ na soja é de 217 mil, dos quais, os $10 \%$ detém $75 \%$ da área cultivada e $77 \%$ do volume produzido, enquanto a agricultura familiar responde pela diferença que não é pequena. Os estabelecimentos na atividade com mais de 1000 ha são 6.080 ou $0.1 \%$ do total, mas produzem (50\%). Na outra ponta os com menos de 10 ha embora representem $18 \%$ dos estabelecimentos, só produzem $1,5 \%$ da safra ${ }^{7}$. Isso reflete a péssima distribuição da terra no país com desigualdades e disparidades únicas no mundo. De acordo com Censo há quase 2,5 milhoes e meio de estabelecimentos com menos de 10 ha (48\%), mas que possuem apenas $2,4 \%$ da área total de 330 milhões de hectares, entretanto 49.911 grandes produtores, com mais de 1000 há açambarcam saiba lá como (44\% das terras) ou 146.553218 milhões de hectares. A Área média entre os dois grupos é de 1000 vezes! E, o índice de Gíni continua muito alto 0,856 (INSTITUTO BRASILEIRO DE GEOGRAFIA E ESTATÍSTICA, 2009).

A importância do Brasil na oferta de commodities agrícola não se resume a soja. O país também é um grande produtor e exportador de café (ao lado da Colômbia), açúcar, (ao lado de União Européia e Índia) carne, suco de laranja (ao lado dos Estados Unidos), álcool, fumo, celulose e outros todos controlados por grandes tradings do comercio internacional (BRASIL, [20--?]).

Os últimos dados da balança comercial mostram a importância que assume as exportações ${ }^{8}$ agropecuárias (e do agronegócio) para a economia, nas ultimas décadas sua participação varia entre 
(31\% em 1997) a (37\% em 2014). Apenas dez complexos $^{9}$ são responsáveis neste período, em media por $90 \%$ do valor total do setor, a participação do complexo soja é a mais representativa (14\%). Três deles concentram cerca de $63 \%$ do setor (Soja, Carne, Álcool e Etanol). Os maiores importadores de 2014 são China, Estados Unidos, Argentina, Países Baixos e Japão (44\%) (BRASIL, [20--?]).

O boom da soja, isto é, o crescimento interrupto da área desde meado da década de1990 levou a uma disseminação da atividade no país com destaque para o Centro-Oeste (48\%) e Sul (34\%). Os Estados do Mato Grosso (30\%), Paraná (17\%), Rio Grande do Sul (15\%) e Goiás (11\%) se destacam, sendo responsáveis por $73 \%$ da produção nacional; dez microrregiões concentram (35\%) e apenas vinte municípios respondem por $(21 \%)$ desta oferta ${ }^{10}$. Ou seja, apesar do grande universo de microrregiões (são centenas) e municípios (são milhares), existente no país a produção da soja é extremamente concentrada.

A comparação entre 2014 e 1990 evidencia outras mudanças em termos espaciais, especializações e (des)-concentrações ao longo desse interstício. Observa-se uma troca de hegemonia, entre Sul (58\%) e Centro-Oeste (32\%), e uma desconcentração da produção sai de $90 \%$ para $72 \%$. Essas mudanças estão associadas ao espraiamento da atividade por todo o país. Esse cenário também se altera entre os entes federados, uns perdendo importância outros ascendendo ${ }^{11}$.

A mudança neste segmento de grãos, onde a soja ${ }^{12}$ e o milho sobressaem foi marcante, especialmente para as regiões de fronteiras e após a alta de preços registrada em meados de 1995. O Brasil em 10 anos dobrar a produção (1995/2005), e mais do que quadriplicar em 24 anos (1995/2014). Fato semelhante aconteceu com o Centro-Oeste. Nordeste e Norte onde essa velocidade foi ainda maior. O primeiro saltou de 1.256 milhões de hectares para 3.960 milhões de hectares e, em seguida para 6.571milhões. Até 1995 a Amazônia (Região Norte) não tinha representatividade, produzia apenas 48 mil toneladas, mas em 2005 já era 1.385 milhões de hectares e, em 2014 chega a 3.522 milhões de hectares ${ }^{13}$.

Até a década de 1990, a soja além dos territórios antigos do Sul e do Sudeste, ela se concentrava praticamente ao Mato Grosso, com inserção esporádica de outros estados da região (Amazônia). Na segunda metade de 1990 esse quadro se altera, com a entrada de outros estados, como Rondônia, Pará, Maranhão, Tocantins, Piauí e Bahia (INSTITUTO BRASILEIRO DE GEOGRAFIA E ESTATÍSTICA, 2015). Constata se que cada cultura se articula com um determinado território e apresenta um grau de concentração regional que varia ao longo do período, mas todas, no entanto, têm como denominador comum o modus operandi e o controle da cadeia por empresas globais nacionais e estrangeiras (INSTITUTO BRASILEIRO DE GEOGRAFIA E ESTATÍSTICA, 2015).

Os reflexos da ênfase no agronegócio pela política governamental são, de um lado, a ascensão da produção e da exportação dessas cadeias agroindustriais; e, de outro, a queda absoluta e relativa da área plantada com arroz, feijão, mandioca e trigo, o aumento dos gastos com importação de alimentos e a desigual apropriação do financiamento público pelas partes envolvidas nessa disputa. A razão desse repentino e duradouro sucesso das commodities, frente ao fracasso da produção de alimentos, se explica pelo cenário nacional e internacional favorável de demanda, preços e política econômica (MESQUITA, 2009).

O problema é o formato que esse modelo agroexportador assume nas fronteiras agrícolas e as conseqüências advindas da concentração e da centralização de capital, que acompanham o seu avanço, já que trazem embutidas novas e velhas questões, como o acesso, o uso e o controle da terra, o acesso à tecnologia, o descarte e o uso da força de trabalho, devastação e a presença de novos e poderosos atores liderando esse processo - as empresas globais, fundos de pensões e holding. Ou seja, o resultado é a amplificação de problemas agrários já existentes, mas também a introdução de outros anteriormente invisíveis, como o custo ambiental e a segregação socioeconômica de populações tradicionais impactadas pelas commodities consubstanciadas em crescentes desterritorializações. Mesmo assim, esse modelo de ocupação e de crescimento econômico realizado pelo capital, baseado em economia de enclaves, socialmente justo e ambientalmente insustentável se mantém a revelia da sociedade (MESQUITA, 2013).

\section{O MODELO AGROEXPORTADOR E AS CONSEQÜÊNCIAS SOCIAIS E AMBIENTAIS}

O atual modelo agroexportador da agricultura produtivista, de larga escala, ao aprimorar sob todos os aspectos aquele padrão que prevalecia no âmbito da Revolução Verde reforçou ainda mais a exclusão social e as desigualdades socioespaciais. As conseqüências da expropriação em termos de deslocamento da força de trabalho, redução na produção de alimentos e do numero de pequenos produtores se associa a devastação generalizada (desmatamento e perda da biodiversidade) que corre paralelamente com a ocupação dos novos territórios pela soja.

Defensores da expansão do agronegócio costumam apontar os seus indicadores econômicos (taxa de crescimento, exportação, produtividade e outros já mostrados) para se capitalizar econômico e politicamente nas suas barganhas. No entanto 
esquecem ou escamoteiam os custos sociais e ambientais advindo desse crescimento econômico a qualquer custo típico da expansão capitalista, para Mesquita (2011a, p. 15-16) no que toca á questão social,

[...] percebe-se que as altas taxas de crescimento sejam do agronegócio ou mesmo da economia como um todo em anos recentes, não têm dado cabo nem ao menos de estabilizar as condições básicas de vida da população, pois a exclusão social ainda campeia uma enorme parcela da população da região. Ao contrário, o modelo econômico vigente tem sido padrasto da maioria da população, especialmente a rural, e dentre desta os grupos que formam os povos e comunidades tradicionais, como os agros extrativistas, quilombolas, indígenas, ribeirinhos, pescadores artesanais, etc.

A razão desta deseconomia de escala ${ }^{14}$ é estrutural, está no pacote tecnológico obrigatório que todos devem adotar que tem por base os elementos da Revolução Verde, qual seja o uso intensivo de insumos, a incorporação crescente de tecnologia, a mecanização dos processos produtivos e a gestão científica da produção, além de novos itens como as sementes geneticamente modificada, e glifosato ${ }^{15}$ introduzido nos anos 1990 no aumento da lucratividade da exploração.

Nesse sentido, o modelo agroexportador atual é muito mais perverso em termos de exclusão social e impacto ambiental do que o seu ancestral colonial (plantation) e seus substitutos posteriores, também usuário de um padrão extensivo de ocupação de terra, especializado, concentrador e lucrativo como o atual agronegócio.

Os conflitos socioeconômicos e ambientais decorrentes da expansão de produtos de exportação e da pecuária extensiva sempre estiveram presente na agricultura brasileira, com menos ou mais intensidade, sobretudo nasáreas de fronteira agrícola. Eles expressam o antagonismo e o tratamento diferenciado dado pelas políticas governamentais a dois segmentos sociais bem distintos no acesso e controle desses territórios. De um lado, pequenos e médios proprietários, não proprietários (ocupantes, arrendatários e parceiros) e categorias específicas como os povos e comunidades tradicionais e grupos indígenas, todos detentores tradicionais seja da propriedade e/ou posse de área onde sobrevivem precariamente. De outro lado, grupos latifundiários, grileiros, grandes posseiros e empresas jurídicas, sedentas pelo controle do acesso a terra livres indispensáveis à expansão dos monocultivos.

Também colabora para o conflito a diferença entre o padrão de expansão do agronegócio e da agricultura familiar. No primeiro, prevalece a lógica da ampliação do capital, da competição acirrada, da centralização do capital e da procura incessante por benécias e lucros. Na outra, o objetivo é, sobretudo pela reprodução da sua força de trabalho. Esse produtor que tem por base o trabalho familiar, a pequena escala, a diversificação da produção, o mercado interno, historicamente nunca conseguiu se capitalizar, pois o apoio de políticas governamentais a esse segmento continua residual ao universo que representa e dessa forma não consegue se livrar dos velhos, e nem dos novos processos de expropriações impostos pelos grupos empresariais a sua permanência na atividade (MESQUITA, 2011a). Sintetizando as conseqüências socioeconômicas que decorrem desse modelo agroexportador, predador de recursos naturais e intensivo em capital são conhecidas de todos, embora algumas delas se diferenciem de acordo com a região, com o nível de organização da sociedade e com o perfil produtivo que prevalece em tal área. A título de exemplo teríamos:

a. Concentração da terra e da renda;

b. Aumento das desigualdades socioespaciais;

c. Aumento da migração campo-cidade e do desemprego rural;

d. A produção da soja gera pouco emprego direto;

e. Expropriação de pequenos e médios produtores - diminui o número de exploração e estabelecimentos agrícolas;

f. Mudança do perfil produtivo regional - mais especialização e concentração da produção;

g. Substituição de policulturas e produção de leite por cultivos monocultivos;

h. Aumento das importações de alimentos e de insumos modernos voltados para o agronegócio;

i. Violência contra lideranças locais;

j. Balança comercial vulnerável - dependência de um número reduzido de produtos.

As conseqüências ambientais da expansão do agronegócio da soja e de outras atividades que cresceu exponencialmente sem um planejamento e acompanhamento adequado pelo Estado, como foi à regra das últimas décadas, trouxe também conseqüências nefastas, irrecuperáveis ao meio ambiente, não só pela dimensão do território ocupado e controlado, mas também pelo modelo e atores do processo. O que se divulga desse processo nos meios mediáticos é apenas a parte mais visível, o desmatamento, mas ele não se esgota ai. O modelo de expansão dominante, como se sabe, aperfeiçoou o pacote tecnológico herdado da Revolução Verde, sofisticando ainda mais uso da química (glifostato) e da genética (transgênicos) do pacote anterior, potencializando assim seus efeitos (negativos) invisíveis, nem sempre computados nas planilhas de custos das empresas. Nessa lista se encontra a contaminação dos solos, lençóis freáticos e de águas 
potáveis e perda de biodiversidade. Especialistas mostram ainda que o uso abusivo de equipamentos pesados, fertilizantes e agrotóxicos ocasiona a compactação, degradação e desequilíbrio do mesmo.

Observa-se que a geografia do desmatamento e a perda de biodiversidade estão intrinsecamente vinculadas à ocupação da fronteira pelo agronegócio (incluindo a pecuária); e isso vale para qualquer lugar onde esteja. Há uma correlação positiva entre a expansão das áreas do agronegócio com a devastação e, portanto com a perda de biodiversidade e com o desmatamento. No Brasil, nesse período recente (pós-1990) ela está presente, sobretudo no Centro-Oeste e em áreas da Amazônia e do Nordeste, locais da mais nova fronteira agrícola das commodities, principalmente de grãos, mas também do eucalipto, do dendê e do capim (MESQUITA; LIMA, 2015). No caso do Cerrado do MATOPIBA uma serie de fatores tem contribuído para a expansão dessas atividades, tais como o credito subsidiado e os incentivos fiscais (exemplo, Lei Kandir), o baixo preço da terra, a expansão da Ferrovia Norte-Sul em conexão com a Carajás, a ampliação do Porto do Itaquí, carta branca dos governos estaduais/municipais quanto a questão ambiental, dentre outros aspectos, o resultado é que em 20 anos (1990-2014) a produção de soja cresceu mais de oito vezes, apesar da precária infraestrutura de serviços e escoamento ainda dominante no local.

No Brasil, a área de ocupada com as culturas do agronegócio é gigantesca ultrapassa a casa das dezenas de milhões de hectares e desde os anos 1990 se encontra predominantemente nos biomas: Cerrado, Pantanal e Amazônico. Nos dois últimos há uma preocupação institucional com apoio inclusive internacional para conter o desmatamento e suas conseqüências, que nem sempre surte efeito, no Cerrado, no entanto, a preocupação governamental é mínima, o que facilita a ocupação e, portanto, o processo de degradação que acompanha a retirada das florestas nativas.

Considerando-se que a Amazônia Legal ${ }^{16}$ inclui os dois biomas (Pantanal, Floresta Amazônica e parte do terceiro), e é onde se encontra a dinâmica atual da expansão dos principais produtos do agronegócio, nota-se que até houve uma queda do desmatamento em vinte anos (1990 a 2010) de $49 \%{ }^{17}$, saindo de $13.730 \mathrm{~km} 2$ para $7.000 \mathrm{~km} 2$. Mesmo assim, a dimensão absoluta ainda é enorme (700.000 hectares). Na década de 1990, o desmatamento cresce $33 \%$ (salta de 13.730 para $18.226 \mathrm{~km} 2$ ), com um pico de $29.059 \mathrm{~km}^{2}$ em 1995, o maior de todos os tempos.Na década seguinte, isto é , de 2000 a 2010, em função das pressões internacionais, registra-se uma queda de $61,6 \%$ (passa de 18.226 $\mathrm{km}^{2}$ para $7.000 \mathrm{~km}^{2}$ ), mas ocorre também o segundo maior pico em 2004, com $27.772 \mathrm{~km}^{2}$. Apesar da queda absoluta nos dez anos (2000-2010), houve um aumento no acumulado (Brasil), ele salta de 220.473 $\mathrm{km}^{2}$ para $385.783 \mathrm{~km}^{2}$, isso equivale a 16,5 milhões de hectares desmatados (INSTITUTO NACIONAL DE PESQUISAS ESPACIAIS, 2011; MESQUITA; LIMA, 2015).

Os dados do INPE (2011) mostram que há uma correlação direta entre estados expoentes do agronegócio (soja, eucalipto, palma africana ou pecuária) como o Mato Grosso, Pará, Rondônia e Maranhão, com participação e a representatividade do desmatamento acumulado. A título de exemplo, no período de 1988 a 2014, nota-se que o Pará (34\%) e o Mato Grosso (34\%) respondem por $68 \%$ do desmatamento da Amazônia e cumulativamente já desmataram respectivamente $138.289 \mathrm{~km}^{2}$ e 137.923 km² da mesma. O Pará está na Amazônia clássica, o desmatamento aqui se articula com a expansão da pecuária e na atualidade com a soja, e no Mato Grosso região de cerrado, o desmatamento acompanhou a expansão primeira da pecuária e depois de grãos, em particular da soja (MESQUITA; LIMA, 2015).

\section{CONCLUSÃO}

Dos diversos aspectos que chamam a atenção na analise da importância econômica (e, política) na evolução e mudança do modelo agroexportador, dois se destacam por ser o cerne da questão. Um é a demanda externa como elemento dinamizador e central desta expansão e, o de provedor de excedente para gerar divisas (industrialização/acumulação). O outro destaque é o papel exercido pelo Estado (intervenção) na viabilização e conservação desse modelo no processo de acumulação. É bom lembrar que sua atuação sempre esteve presente, do complexo cafeeiro capitalista (via a política de desvalorização da moeda, resolução da oferta de força de trabalho e do acesso a terra, plano de valorização do café, etc.), passando pela crise de 1929 (socializando as perdas dos agroexportadores); a constituição e consolidação nos anos 1970 e 1980 dos complexos agroindustriais (via política de modernização e programas especiais), até o boom do agronegócio dos anos 1990 (com incentivos financeiros, fiscais e investimentos em infraestruturas para exportação). Esse alerta já era nos dados pela professora Maria da Conceição Tavares (1988, p. 26) quando afirma que:

É preciso ter claro que a intervenção do estado sempre foi absolutamente relevante, seja para dar lugar a um processo de industrialização e acumulação capitalista, seja em situação de guerra e reconstrução. De maneira que não adianta que o paradigma liberal diga que o mercado funciona bem, que a intervenção deve ser a mínima possível, porque em crise, em guerra, 
ou no surgimento industrial de qualquer nação, o Estado intervém sempre.

E no caso da criação, consolidação e mudança no modelo agroexportador não foi diferente, do período colonial a atualidade o papel do Estado foi fundamental. Sem sua ajuda o processo de modernização agrícola e seus desdobramentos, em termos de concentração e centralização do capital, essencial na constituição e consolidação de complexos agroindústrias no setor não teriam acontecido na década de 1970 e 1980. Sua ação foi à base da reorganização do setor e da sua volta ao mercado internacional. Mesmo no cenário neoliberal da década de 1990, seu papel na efetivação de políticas macroeconômicas e setoriais condizentes com a globalização comercial e financeira, ao contrario do que se afirma é quem dar visibilidade aos complexos do agronegócio atual, agora centralizados em tradings no cenário da globalização. Dessa forma não foi as forças de mercado, isto é, a entrada de empresas globais na produção de commodities o pilar principal do boom das exportações desse segmento. Foi a atuação do Estado, conforme já analisamos anteriormente, e a conjuntura econômica favorável que explica essa mudança e a manutenção desse modelo agroexportador na atualidade.

Portanto essa atuação do Estado via política setorial e/ou macroeconômica, pratica recorrente da sua ação, não pode ser vista isoladamente ou de forma pontual, mas de acordo com Wesz Júnior (2014, p. 145)

[...] como um conjunto de instrumentos mobilizados para sustentação de um modelo de desenvolvimento agroexportador, que, ao longo dos anos, foi se modificando e reestruturando a partir do contexto políticoeconômico nacional e internacional. É impressionante como esse modelo de política econômica pautado no desenvolvimento agroexportador - que fora destacado por Celso Furtado nas décadas de 50 e 60 , que se orienta pela demanda internacional (principalmente dos países industrializados, mas não só) e que se mantém como provedor de matéria-prima - permanece vigente no momento atual, apesar de algumas adaptações ao contexto contemporâneo.

No entanto mesmo que esse atual modelo agroexportador (ou seja, do agronegócio) detenha os mesmos elementos fundamente daquele padrão anterior, Wesz Júnior (2014, p. 85) baseado em Gras e Hermandez (2013) diz que

[...] nos meios midiáticos e políticoinstitucionais ele é omitido e passa a significar um salto ao futuro, rompendo uma agricultura tradicional para uma

\section{SUAS CONSEQUENCIAS SOCIAIS E AMBIENTAIS}

\begin{abstract}
agricultura inovadora. Esse resultado é reflexo, em grande medida, da atuação crescente das entidades de representação do setor, que passam a usar os meios de comunicação para difusão de tais idéias e ideais.
\end{abstract}

Os arautos do agronegócio esquecem que essa agricultura da inovação, da competividade e da eficiência vem acompanhada de inúmeras conseqüências sociais, econômicas, ambientais e culturais, com efeitos diferenciados em termos temporais e espaciais. Tal fato decorre da presença marcante de grandes projetos na atividade, que de acordo com Vainer (2007), são portadores de um potencial de (des)-organização e transformação dos espaços, aliás, um grande potencial de compor e decompor regiões inteiras. Por sua própria natureza, eles projetam sobre os espaços locais e regionais interesses quase sempre globais, o que os torna globais-locais.

A resultante é de um lado, um processo contínuo de expropriação, que se visualiza em termos de queda da produção de alimentos e encolhimento da agricultura familiar, concentração da terra e da renda e, a disputa desigual por recursos públicos entre agricultores familiares e agricultura empresarial e, de outro, potencialização do impacto ambiental (MESQUITA, 2013).

\section{REFERÊNCIAS}

BRASIL. Ministério da Agricultura, Pescuária e Abastecimento. Exportações do agronegócio. Brasília, DF, [20--?]. Disponíveis em: <http://www. agricultura.gov.br/exportacoes-do-agronegocio> Acesso em: 15 jul. 2015

CANO, W. Raízes da concentração industrial em São Paulo. São Paulo: T. A. Queiroz, 1983.

CASTRO, A. B. 7 ensaios sobre a economia brasileira. Rio de Janeiro: Forense-Universitária, 1977.

DAVIS, J. H.; GOLDBERG R. A. A concept of agribusiness. Boston: Harvard University, 1957.

DELGADO, G. C. Do capital financeiro na agricultura à economia do agronegócio: mudanças cíclicas em meio século. Porto Alegre: UFRGS, 2012

FURTADO, C. Formação econômica do Brasil. São Paulo: Ed. Nacional, 1997.

GRAS, C. Agronegocios en el Cono Sur. Actores sociales, desigualdades y entrelazamientos transregionales. Working Paper, Berlin, n. 50, 2013. GRAZIANO DA SILVA, J. A nova dinâmica da 
agricultura brasileira. Campinas, SP: UNICAMP, 1996.

INSTITUTO BRASILEIRO DE GEOGRAFIA E ESTATÍSTICA. Banco de dados agregados. Rio de Janeiro, 2015. Disponível em:<http://www.sidra. ibge.gov.br>. Acesso em: 25 abr. 2015.

2009.

. Censo agropecuário 2006. Rio de Janeiro,

INSTITUTO NACIONAL DE PESQUISAS ESPACIAIS. Projeto Prodes. São José dos Campos, 2011. Disponível em:<http://www.prodes. gov.br>. Acesso em: 7 jul. 2013.

KAGEYAMA, A. et al. O novo padrão agrícola brasileiro: do complexo rural aos complexos agroindustriais. In: DELGADO, G. C. (Org.). Agricultura e políticas públicas. Brasília, DF: IPEA, 1990. p. 113-223.

MARX, Karl. O Capital. 2. ed. Rio de Janeiro: Civilização Brasileira, 1971. Livro 1, v II, cap. 24.

MESQUITA, B. A. de. A atuação governamental, as forças de mercado e a inserção da Amazônia no ciclo de commodities, In: COUTINHO, J. A.; LOPES, J. B. (Orgs). Crise do capital, lutas sociais e políticas públicas. São Paulo: Xama, 2012.

Conflitos territoriais na Amazônia na "Era do capital. In: SHIRAISHI NETO, J. et al. (Orgs.). Meio ambiente, território e práticas jurídicas: enredos e conflitos. São Luís: EDUFMA, 2011a.

. Demanda por alimentos e as conseqüências na Amazônia brasileira: "sucesso" do agronegócio e tragédia do desmatamento. In: ENCONTRO DE GEÓGRAFOS DA AMÉRICA LATINA, 2009, Montevidéu. Anais... Montevidéu, 2009.

Expansão e transformação da pecuária bovina no Maranhão sob a ação governamental e as forças de mercado: ritmos e rumos da ação do capital no período de 1970/200. 2006. 485 f. Tese (Doutorado em Políticas Políticas) - Programa de Pós-graduação de Políticas Públicas, Universidade Federal do Maranhão, São Luís, 2006.

O desenvolvimento desigual da agricultura: a dinâmica do agronegócio e da agricultura familiar. São Luís: EDUFMA, 2011b.

Os grandes projetos de investimentos na Amazônia e as transformações agrárias. Évora: ESADR, 2013.

; LIMA, L. A. P. A expansão de monocultivos de soja e eucalipto nos cerrados do Tocantins e Maranhão e a organização do espaço agrário e do perfil produtivo destas economias. In: ENCONTRO DE GEÓGRAFOS DA AMÉRICA LATINA, 15, 2015, Havana. Anais. Havana, 2015.

OLIVEIRA, F. de. A economia brasileira: critica a razão dualista. São Paulo: CEBRAP, 1975. (Caderno n. 1).

PRADO JR, C. Historia econômica do Brasil. São Paulo: Ed Brasiliense, 1976.

TAVARES, M. C. O planejamento em economia mista. In: HADDAD, P. R.; EDLER, P. S. Estado e Planejamento: sonhos e realidades. Brasília, DF: CENDEC, 1988. p. 25-52.

VAINER, C. Planejamento territorial e projeto nacional: os desafios da fragmentação. Revista Brasileira de Estudos Urbanos e Regionais, Recife, v. 9, n. 1, maio 2007.

WESZ JUNIOR, V. J. O mercado da soja e as relações de troca entre produtores rurais $\mathrm{e}$ empresas no Sudeste de Mato Grosso (Brasil). 2014. 225 f. Tese (Doutorado em Ciências Sociais) - Programa de Pós-graduação de Ciências Sociais em Desenvolvimento, Agricultura e Sociedade, Universidade Federal Rural do Rio de Janeiro, Rio de Janeiro, 2014.

\section{NOTAS}

O texto é um roteiro ampliado da discussão da mesa "A expansão do agronegócio e a produção de alimentos na América Latina: a contribuição governamental a centralização do capital e a exclusão social", realizada na joinpp2015.

2 Entre 2000 a 2014 as exportações brasileiras cresceram $376 \%$, a do agronegócio $473 \%$ e a da agropecuária $586 \%$. Em termos de participação nas exportações gerais o agronegócio sai de $37 \%$ para $43 \%$ e a agropecuária de $24 \%$ para $37 \%$. A contribuição da agropecuária nas exportações dobrou (16\% para $32 \%)$ e do agronegócio cresceu (27\% para $36 \%$ ) (BRASIL, [20--?]).

3 Na última década, em função deste cenário favorável houve uma corrida a compra de empresas brasileiras de setores estratégicos como da biocombustíveis,por grupos Americanos e franceses.Foi também detectado nas áreas de fronteira o arredamento e compra de imensas áreas de terras por grupos estrangeiros como formas de garantir uma expansão futura e aproveitar o boom das commodities ,isso sem qualquer controle de órgãos governamentais (MESQUITA,2013) .

4 Entre 1990 a 2014, foi marcante o declínio relativo da área com produtos básicos arroz, feijão e trigo (em relação a área total de lavoura temporária ).O arroz caiu de $9 \%$ para $3,3 \%$; o feijão $11,5 \%$ para $4,8 \%$ e o trigo $7,3 \%$ para $4 \%$.A proporção da área 
dessas culturas frente a área com a soja também é declinante,em 1990, os três produtos representavam $110 \%$ da área de soja .Em 2014 a soma da área das três culturas representavam apenas $28 \%$ da área de Soja, isto é, houve um encolhimento marcante no período (INSTITUTO BRASILEIRO DE GEOGRAFIA E ESTATÍSTICA, 2015)

5 Área do MATOPIBA é a denominação dada à área situada ao Sul do Maranhão e do Piauí, Leste do Tocantins e Oeste da Bahia, a estimada em cerca de $70 \mathrm{mil} / \mathrm{km}^{2}$.

6 Censo de 2006 dividiu os estabelecimentos em familiar e patronal. Na primeira estaria aquele com área inferior a 200 ha e a patronal com mais de 200 ha. No Brasil de acordo com IBGE há 5.130 milhões de estabelecimentos ocupando uma área de 330.680 milhões de hectares dos quais

7 No caso da mandioca é o inverso, no trigo e arroz a participação é meio a meio. Em termos de volume(t).A tendência com a entrada de grandes grupos nacionais e internacionais na soja é que a concentração tenha se acentuado.

8 Aexportação da agropecuária compreende a exportação agrícola e pecuária, enquanto a do agronegócio envolve a atividade em si e seus elos industriais a jusante (indústria processadoras) a montante (indústrias fornecedoras de bens e serviços) vinculado a atividade.

9 Os mais importantes complexos são: soja, carne, café, fumo, sucro-alcooleiro, celulose, laranja, milho e algodão.

10 Em área plantada, o ranking segue o mesmo padrão, com o Mato Grosso em primeiro lugar, o Paraná em segundo e o Rio Grande do Sul em terceiro.

11 Os estados do Sul e Sudeste cedem posição aos do Centro-Oeste e do Nordeste. Em 1990 os cinco maiores produtores são os mesmos de 2014. O que altera é a ordem de importância e a participação no total geral $87 \%$, sendo os dois primeiros Rio Grande do Sul (32\%) e Mato Grosso (30\%). Das 10 microrregiões (1990) que respondem por $36 \%$ da produção (5) estão no RGS, (2) no MT e PR e MTS e GO apenas uma. Em 2014 (6) estão no MT e as demais (4) estão distribuídas com MTS, GO, PR e BA (INSTITUTO BRASILEIRO DE GEOGRAFIA E ESTATÍSTICA, 2015).

12 Simultaneamente a essa expansão vigorosa da soja, outras monoculturas, como o dendê e o eucalipto, rapidamente despontam no cenário amazônico, só que em ritmo menos acelerado. Ambas estão também articuladas a essa dinâmica externa e interna que lhes favorece. De um lado, o lançamento de programas voltados para os bicombustíveis e de substituição de óleo de palma, e, de outro lado, os preços e a demanda internacional crescente, que, somados à oferta generosa de recursos públicos para financiamento de tais investimentos de longo prazo, constituem, sem dúvida, fator de atração para esses complexos agroindustriais que controlam os segmentos da celulose, gusa e biocombustíveis.

13 Apesar da soja já Amazônia desde o final dos anos 1990, efetivamente ela entrar o coração da Amazônia (Santarém/PA) , consolida e se generaliza em 2005. provoca um aumento no custo de produção.

15 É um herbicida sistêmico não seletivo (mata qualquer tipo de planta) desenvolvido para matar ervas principalmente perene, mas as sementes produzidas pela Monsanto resistem ao herbicida.

16 Amazônia Legal é constituída da Região Norte mais os Estados do Mato Grosso e parte do Maranhão.

17 Todos os dados relativo a desmatamento tem como fonte o INPE (2011).

\section{Benjamin Alvino de Mesquita}

Economista

Doutor em Geografie, Amenegement et Urbanism pelo IHEAL/Sorbonne Nouvelle/Paris III

Professor Associado do Departamento de Economia e Professor Permanente dos Programas de PósGraduação em Políticas Públicas e de Desenvolvimento Socioeconômico da Universidade Federal do Maranhão (UFMA)

E-mail: bamin@uol.com.br

\section{Universidade Federal do Maranhão - UFMA}

Cidade Universitária Dom Delgado

Av. dos Portugueses, n. 1966, Bacanga, São Luís/MA CEP: $65085-580$ 